\title{
LA FIGURA DE PAOLINA EN EL LEOPARDISMO ARGENTINO
}

\author{
THE FIGURE OF PAOLINA IN ARGENTINEAN LEOPARDISM
}

\author{
Miquel Edo \\ Universitat Autònoma de Barcelona. Barcelona, España \\ Miquel.Edo@uab.es
}

Recibido: 20.11.2013. Aceptado: 12.03.2014.

Resumen: Paolina Leopardi aparece como protagonista -junto a su hermano Giacomo- de un capítulo de Las hermanas tutelares de Rafael Alberto Arrieta (1923), del cuento "Hermanos" de Enrique M. Butti (1993) y de la novela Después del día de fiesta de Griselda Gambaro (1994). En los tres casos su figura es mitificada, en buena parte, en detrimento de la de Giacomo, perfilándose un interés en buscar un Leopardi al femenino, dotado de la fuerza sentimental y estética propia del arquetipo de la mujer que ama o es amada en la ausencia y la lejanía.

Palabras clave: Leopardi, epistolarios, desmitificación, incesto, lejanía.

\begin{abstract}
Paolina Leopardi appears as a protagonist -along with her brother Giacomo- in one of the chapters in Las hermanas tutelares by Rafael Alberto Arrieta (1923), the short story "Hermanos" by Enrique M. Butti (1993) and the novel Después del día de fiesta by Griselda Gambaro (1994). In each of these cases she is presented as a mythical figure, to a large degree, in detriment to that of Giacomo, which illustrates an interest in searching for a Leopardi in the feminine, endowed with the emotional and aesthetic force emblematic of the archetypal woman who loves or is loved in absence or from afar.
\end{abstract}

Key words: Leopardi, epistolary genre, demythologization, incest, distance.

A RECEPCIÓN DE LEOPARDI en tierras argentinas aporta por lo menos tres
trabajos que conceden un alto grado de protagonismo a la hermana del 
poeta. Dos de ellos son bastante conocidos: el capítulo sobre Paolina incluido en Las hermanas tutelares, de Rafael Alberto Arrieta, volumen publicado en 1923 (Del Greco, 1952: 253; Galli de Ortega, 1999: 1225; Blanco de García, 2008: 29, 32), y la novela de Griselda Gambaro Después del día de fiesta, del año 1994 (Blanco de García, 1998: 263-267; Galli de Ortega, 1999: 1228; Blanco de García, 2008: 29, 99-100, 340, 342, 516). El tercero ha sido señalado por Adriana Crolla: se trata del breve cuento "Hermanos" de Enrique Manuel Butti, perteneciente al libro SolFeo, de 1993 (Crolla, 2008: 42). Se inscriben, los tres, en géneros, poéticas y contextos muy alejados entre sí. Arrieta, a diferencia de Gambaro y Butti, no ficcionaliza: el suyo es un ensayo con toques lírico-sentimentales, pero ensayo al fin y al cabo, en el que básicamente se historiza a la manera clásica. Anticipa la extensa producción erudita de su autor, a la vez que contiene ecos de la carrera poética que había desarrollado sobre todo en sus años jóvenes, dentro de la corriente sencillista del posmodernismo y con una predilección especial por la vida doméstica y los afectos familiares. Enraizada en la literatura de la dictadura y de la violencia, la obra de Griselda Gambaro entra en intersección, en Después del día de fiesta, con la nueva novela histórica: el texto está ambientado en la Argentina contemporánea, por lo que no puede encuadrarse estrictamente en dicho subgénero, pero en este Buenos Aires de 1994 aparece, buscando a su hermana, Giacomo Leopardi, anacronismo que, junto con las estrategias de intertextualidad y carnavalización a que más adelante nos referiremos, sí responde al modelo teorizado por Menton, Aínsa o María Cristina Pons. Si, por otra parte, Arrieta se ceñía a convenciones claramente prefeministas, con unas hermanas que no superaban el estatus de ayudantes de los hermanos, en Gambaro la denuncia de la mujer víctima se sitúa en un primerísimo plano merced al destacado papel que se otorga, entre los personajes, a Paolina y a la joven de color N'Bom. No faltan, así, en Después del día de fiesta, dos características que se han observado específicamente en la nueva novela histórica escrita por mujeres (Perkowska, 2008: 225-226, 257; Biasetti, 2009: 53-57, 119-120; Grillo, 2010: 92-96): el poner en paralelo la marginación de género con la de colectivos étnicos (en este caso los inmigrantes africanos e indostánicos) y el dar voz a la mujer para que sea ella quien hable de sí misma (las cartas de Paolina a Giacomo). En lo que respecta a Butti, pese al año escaso que separa su cuento de la novela de Gambaro, se mueve en parámetros que 
nada tienen que ver con la literatura comprometida o feminista: el santafesino hace una apuesta decidida por lo fantástico, por un absurdo de corte más radical y kafkiano, por un psicologismo paranoico. Resulta significativo, pues, que tres autores tan distintos de un mismo país no sólo se hayan fijado en esta figura secundaria de la historiografía italiana, sino que hayan dibujado un escenario en el que, en parte, la identificación y solidaridad entre los dos hermanos en torno a sus desventuras determina que Paolina arrebate a Giacomo la titularidad de las mismas y, con ellas, en cierto sentido, de su obra literaria; en parte, la mitificación de Paolina como personaje e incluso como escritora se lleva a cabo a costa de una desmitificación de Giacomo.

En cuanto a la primera de estas dos maniobras, hay que empezar señalando que Arrieta, Gambaro y Butti centran su relato en el punto en que la vida de los dos hermanos se bifurca o ya se ha bifurcado: Giacomo huye de Recanati, Paolina no lo consigue. Ambos comparten el sentimiento de opresión ante la mentalidad estrecha de su ciudad y, sobre todo, de sus progenitores, refugiándose en un amor fraternal que persiste más allá de la separación y se vehicula, en Arrieta y Gambaro, como en la realidad histórica, a través de la correspondencia que mantienen, tomada principalmente -en ambos casos- del pequeño volumen de Carlo Pascal La sorella di Giacomo Leopardi (1921). Arrieta subraya que el odio a Recanati aparece en las cartas de Paolina "casi con las mismas expresiones del poeta" (1923: 80), comenta, entre otros, un fragmento de dichas cartas del que subraya el "humorismo ácido" (84) y escoge pasajes cercanos a la negación leopardiana de la esperanza (78-80). Gambaro no reproduce la correspondencia original a modo de cita, sino que basándose en ella y en las informaciones de los biógrafos elabora cartas que la Paolina real, en esos términos exactos, no escribió o escribió sólo parcialmente. Frente al uso documental del epistolario por parte de Arrieta, se implementa aquí uno de los estatutos narrativos de la nueva novela histórica, el palimpsesto, que sirve a su vez de canal de entrada de algunos presupuestos básicos del feminismo literario: la recuperación de voces de mujeres negligidas por la historiografía literaria oficial, la atención a los géneros menores de perfil autobiográfico e intimista, la denuncia de una condición de cautividad y una búsqueda de la propia identidad femenina (Ciplijauskaité, 2004; Abud Martínez, 2008; Biasetti, 2009; Grillo, 2010), todos ellos potenciados por la superposición 
de la voz ficticia de la narradora implícita a la voz de la figura histórica. Las primeras cartas son muy libres (Gambaro, 1994: 28-31, 43-47), mientras que a medida que avanza la novela se da más cabida a largos fragmentos traducidos del epistolario auténtico, aunque siempre alternados con redacción nueva (6o-63, 85-89, 122-124, 138-140, 146-153), entre otras cosas por las modificaciones que impone, por un lado, el engarce de fragmentos sacados de distintas cartas y, por otro, el que la correspondencia históricamente dirigida a las amigas Marianna y Anna Brighenti pase aquí a tener por destinatario a Giacomo (Morell, 1997: 667-668; Tarantuviez, 2001: 87); pero también porque a Gambaro le interesa desarrollar determinados temas. A veces, en vez de traducir, más bien parafrasea, resumiendo o dilatando. Otras veces traduce o parafrasea no a Paolina, sino a los biógrafos, y entre el material fundido también lo hay de origen leopardiano, desde esporádicas citas veladas hasta la reelaboración narrativa de un famoso apunte del Zibaldone (1994: 149-151). Si a estas apropiaciones sumamos, como en Arrieta, aquellos fragmentos traducidos sí del epistolario real y afines ya allí al lenguaje y pensamiento leopardianos (véase, por ejemplo, la envidia hacia los campesinos por su vida menos torturada por la reflexión: 85, 165-168; Pascal, 1921: 8), tenemos, pues, una Paolina no desbordante, pero sí con altas dosis de leopardismo.

Más interesante resulta, en cualquier caso, que la mitificación de esta figura femenina, aun cuando se alimenta de la adoración que por ella sentía su hermano, redunde en perjuicio de éste. En Arrieta, Paolina es caracterizada a mitad de camino entre la heroína romántica y la santa ascética. De la primera tiene el dolor del cautivo y sus sueños de libertad, el apasionamiento amoroso y su frustración, la complacencia en el desespero. De la segunda, el carácter abnegado y reprimido, la capacidad de soportar y sacrificarse, así como una bondad incorruptible. Ella es quien tempera los conflictos entre los miembros de la familia, contraponiendo su perfil equilibrado al radicalismo de los extremos: la religiosidad intolerante de la madre y el ateísmo a ultranza del hermano. No se la acusa por no huir: se da por sentado que su condición femenina la imposibilitaba a hacerlo. Se le recrimina, a propósito de los proyectos de matrimonio fallidos, falta de confianza, pero tales fracasos no hacen sino añadir motivos a la infelicidad con la que se dibuja su aura. También Giacomo se sitúa, desde luego, en este cuadro de patetismo decimonónico, pero su retrato es más ambiguo. 
Notemos cómo en la frase referente a su huida se infiltra el término "envenenada": "Cuando dejó su casa y su pequeña ciudad, llevaba ya envenenada el alma y deshecho el cuerpo” (1923: 73). Arrieta hace suya no sólo la inclusión de Giacomo, ya propuesta por Pascal (1921: 17-18), en el sector de los "temperamentos dominadores y caracteres intransigentes" de la familia (1923: 78), sino también la desautorización de que había sido objeto el poeta, por parte de la propia Paolina y de Francesco De Sanctis, en lo relativo al fuerte resentimiento que sentía hacia su padre (75; Pascal, 1921: 23-24).

En Después del día de fiesta Paolina es igualmente, por encima de todo, una víctima, por un lado de unos padres posesivos, y sobre todo de una madre controladora y puritana, por otro lado de unos pretendientes egoístas, incapaces de estar a la altura de los sentimientos que ella les profesa. Se erige, mucho más que en Arrieta, en una clara representante del sometimiento de la mujer en lo que podríamos llamar el Antiguo Régimen (Saint André, 1998: 82-84; Capano, 2000: 214-217; Tarantuviez, 2001: 89), sin que por ello pierda vigencia la heroína romántica, en la medida en que se da mucho espacio al tormento interior de una personalidad en la que tan exacerbadas se muestran la pasión y las ansias de amor y libertad como la autorrepresión de las mismas. El propio personaje se interroga sobre su incapacidad de rebelión, pero no queda menos clara su incapacidad para el odio -la santa ascética-, y aunque quepa la posibilidad de tacharla de heroína fallida colocándola junto a las numerosas protagonistas gambarianas que colaboran con sus opresores mediante una sumisión pasiva (Tarantuviez, 2001: 36-37, 51-52, 130), no deja de ser, junto a Tristán, la figura que despierta más simpatías de la novela, en buena parte merced a la verbalización y elaboración literaria de su sufrimiento y al alto grado de conciencia que adquiere de su situación y de sus propias contradicciones y limitaciones. Arrieta y Gambaro, pues, no sólo dan una visión bastante coincidente del personaje, sino que tampoco se alejan demasiado de la Paolina histórica tal como la describen las fuentes y tal como ha sido estudiada $\mathrm{y}$-por lo menos hasta cierto punto- ensalzada por los estudiosos ${ }^{1}$ : incluso

${ }^{1}$ Pese al interés más bien relativo de su epistolario, la crítica le ha reservado un pequeño pedestal en el canon de la literatura femenina del siglo xix (Dolfi, 1991; Benucci, 2003). También en Italia, por lo demás, se la ha considerado símbolo de la opresión plurisecular de las mujeres (Bellucci, 2010: 9-10) o se ha destacado la ambivalencia de la actitud que muestra hacia sus opresores (Gioanola, 1995: 59-62). 
en los pasajes más libres Gambaro se esfuerza mucho en identificarse con ella, dotándola de menos recato y más franqueza, pero siempre dentro de una más que lograda verosimilitud. La escritora bonaerense da, además, una vuelta de tuerca final en su mitificación del personaje mediante un curioso amago con el que empaña momentáneamente su imagen. Paolina se presenta junto a Antonio Ranieri para asistir al fallecimiento de Giacomino, pero el moribundo la recibe con indiferencia y a Tristán no le causa la impresión favorable que cabría esperar, hasta que este último descubre que no se trata de Paolina Leopardi, sino de Paolina Ranieri (Gambaro, 1994: 185-189, 192): la coincidencia en el nombre de pila ha propiciado un equívoco del que el prestigio de la hermana de Giacomo sale, pues, indemne en su fabulosa e incontaminada lejanía.

Considerablemente distinta, y sobre todo menos verosímil, la conformación que recibe, en Después del día de fiesta, el personaje de Giacomo. Se cargan aquí las tintas en el Leopardi más enfermo e inadaptado. No sólo se hace hincapié en su físico escuchimizado, en el cansancio que le atenaza al mínimo esfuerzo, en la tristeza que lleva estampada en el rostro, sino que los trastornos nerviosos, en las fuentes históricas recurrentes pero poco definidos, se concretan en un baile de san Vito constante y en un don para romper todo lo que cae en sus manos, probable hiperbolización -por más que la autora afirme que son datos verídicos (André, 2004: 67)- de la anécdota referida por Monaldo acerca de los hábitos de su hijo como comensal (Gambaro, 1994: 82-83; Capano, 2000: 210). Se revela absolutamente negado para cualquier aspecto de la vida práctica, necesitado de protección y atención permanente, la que le presta el sufrido Tristán, que hace las veces de asistente social y le trata -no tiene más remedio- como a un crío tonto a quien hay que avisar y regañar continuamente, a lo que a su vez él responde sin atisbo alguno de gratitud, absorto en su mundo de lecturas y cavilaciones o portándose como un señorito maniático y orgulloso. Pueril en sus momentos de entusiasmo, exhibe unas alteraciones anímicas que se combinan con un ejercicio espasmódico de la escritura, casi como si ésta no fuera más que una obsesión sin sentido. Los recuerdos y relatos del entorno familiar que en Paolina, pese a la desesperación, guardan siempre un mínimo de serenidad, se hacen en él más crispados y traumáticos. Los pasajes ya sea del Zibaldone, ya sea de los Pensieri o de las Operette morali, que, parafraseados o pseudotraducidos, se ponen en su boca, son intercalados 
en la narración muy fragmentariamente, de modo que suscitan un efecto de fogonazos inconexos y estrafalarios. Tristán a veces suscribe y reutiliza estas ideas, e incluso en algún momento las reconoce como el producto de una mente privilegiada, pero en otras ocasiones las rebate, acusando a su huésped de ser autorreferencial o elitista, o las juzga absurdas y cargantes. Vemos siempre a Giacomo desde la perspectiva del protagonista, cuya menor preparación intelectual es compensada por un mayor sentido común y un mayor conocimiento de la vida, lo que le convierte en un interlocutor más digno de crédito. Que esta perspectiva pueda verse corregida por lo que el lector culto o sagaz sabe o adivina acerca de Leopardi, no implica que quede anulada. El objetivo de Gambaro quizá no fue negativizar al personaje, sino sólo incorporarlo a la galería de almas desamparadas que pueblan su universo, y sin duda su retrato está condicionado por la compasión que debe despertar en Tristán, pero lo cierto es que dichos fines se alcanzan caricaturizándolo - protagoniza los momentos más cómicos de la novela- y haciendo de él prácticamente un discapacitado. En la ficcionalización gambariana, tanto Giacomo como Paolina están en el bando de los perdedores, pero la carnavalización grotesca con que la nueva novela histórica desacraliza las grandes figuras del pasado se ceba mucho más con él que con ella, casi en razón inversamente proporcional a la grandeza que, de acuerdo con su género respectivo, la historiografía oficial otorgaba a uno y a otra.

Un año antes de la publicación de Después del día de fiesta, y sin que haya constancia de contacto alguno entre ambos autores, la ineptitud y el fracaso de Leopardi como persona ya habían centrado la breve recreación de la huida del hogar paterno esbozada por Enrique Manuel Butti. Hay que aclarar, ante todo, que no aparecen, en "Hermanos", ni el nombre de Giacomo ni el de Paolina, y tanto menos el apellido Leopardi. La vinculación de los protagonistas con los hermanos de Recanati parte de declaraciones del propio Butti de las que se hace eco la estudiosa Adriana Crolla: "Butti reconoce que uno de los cuentos de su libro SolFeo, editado en México, tiene una directa inspiración leopardiana. El cuento se titula 'Hermanos"' (2008: 42). Se trata de un mini-relato escrito, decíamos, desde una poética radicalmente irrealista -más irrealista que el salto geográfico y temporal de Gambaro-. Los padres yacen amortajados en un dormitorio matrimonial que es a la vez cámara fúnebre, el protagonista decide escapar pero en realidad termina por hacerlo dentro de casa: 
Después fingí salir a la calle golpeando la puerta de entrada. Me escondí detrás del baúl, en el entretecho del garage [sic], y pasando de ahí a los roperos, a la despensa o bajo las camas, empezó esta fuga que ya dura veinte años (Butti, 1993: 67-68).

Antes ha cruzado el dormitorio de los padres, donde ha tropezado con la alfombra y ha provocado un estropicio. También ha ido a despedirse de su hermana:

-Dora... Dorita -murmuré. En la oscuridad sentí su manita que me buscaba. -Me tengo que ir, me escapo -dije.

Me apretó fuerte:

-¿Me voy a quedar sola, entonces?

Era inútil contestarle. Son cosas que cada uno debe entender por su cuenta. Quizás algún día nuestros caminos volvieran a encontrarse. Llevé su mano bajo las colchas y me desprendí de ella (67).

Dentro de las interpretaciones posibles del cuento, es perfectamente lícita la de un Leopardi físicamente torpe y psicológicamente incapaz de superar la sujeción a sus odiados padres, así como de enfrentarse al mundo exterior. Más que en Arrieta y Gambaro, además, la huida se presta a ser leída como un abandono de Paolina: la conversación entre los hermanos empieza con la mano de ella buscando la de él y termina con la mano de él que, literalmente, se desprende de la de ella. No se describe un sentimiento de necesidad mutua: Paolina necesita a Giacomo y éste piensa sólo en sí mismo. No parece que le preocupe mucho la posibilidad de que no vuelvan a verse, y el "Son cosas que cada uno debe entender por su cuenta" suena a autojustificación para quedarse con la conciencia tranquila. Quizá sea verdad -como reza la frase inicial- que "estaba ante la última oportunidad que se [le] ofrecía para escapar" (67), pero los motivos de esta prisa repentina, así como de que no se lleve con él a Paolina-Dorita, quedan envueltos en un misterio que, como el que afecta al Leopardi de Después del día de fiesta, más bien arroja dudas y sombras sobre el personaje y nos invita a ver en él trazas de insensibilidad y de un escaso sentido de lo real. La deformación grotesca de Gambaro encuentra así una correspondencia en el humor irracional y disparatado característico de la prosa del escritor santafesino, obsequiándonos ambos con una criatura casi de ciencia ficción, más pos- 
moderna que antigua, o - para decirlo con mayor exactitud- a la vez lúdica e inquietante en su posmodernidad.

Volviendo a Arrieta y Gambaro, otro dato que da fuerza a la lectura desmitificadora es el peso que la poesía leopardiana cede, en sus respectivos textos (Butti no efectúa cita alguna), frente a la correspondencia y, en especial, frente a las cartas que escribe Paolina. Arrieta cita veinte versos de Le ricordanze y diecisiete de Nelle nozze della sorella Paolina, sólo algún pequeño extracto de la correspondencia escrita por Giacomo y, en cambio, una docena de fragmentos de las cartas de su hermana, la mayoría de considerable extensión. Prácticamente todo el capítulo se presenta como el resultado del descubrimiento de un epistolario gracias al cual nos es dado conocer un "drama interior" -el de Paolina- que de otro modo habría pasado desapercibido (Arrieta, 1923: 77). En Después del día de fiesta lo único que se cita de los Canti son los versos 16-17 de Nelle nozze della sorella Paolina, 70-71 de La vita solitaria, 1-3 de Le ricordanze y 1-6 y 23-24 de La sera del di di festa (Gambaro, 1994: 43, 109, 109-110, 169-170, 179, 194196). Se reiteran a modo de leitmotiv, a lo largo de toda la novela, la frase "a tutti il risvegliarsi è danno" (Cantico del gallo silvestre, § 3) y, sobre todo, el verso inicial de La sera del dí di festa, "Dolce e chiara è la notte e senza vento": Tristán lo pronuncia sin saber de dónde procede, le viene a la cabeza repetida y maquinalmente sin que se le ocurra relacionarlo con su huésped Giacomo, y sólo al final, poco antes de fallecer éste, un día en que echa un vistazo a sus papeles, descubre que es suyo. La frase ejercía sobre Tristán un efecto balsámico y revelatorio: hacía que el mundo pareciera, de pronto, un lugar apacible, lo que le llevaba a pensar que si diera con el resto del poema quizás éste obraría el milagro de sacar a sus vecinos de la miseria y la marginación. Ahora, cuando lo ha encontrado, tales ilusiones se han evaporado, puesto que lo que ha leído no encierra contenido social alguno. Es así negado el poder taumatúrgico de la poesía, para ser recuperado in extremis, en el último párrafo, con la idea de que la belleza no transforma la sociedad, pero sí el corazón de las personas, al mostrarles una realidad más bella que la que les rodea. Este tema, la función de la poesía con respecto al desolador panorama social de los suburbios de Buenos Aires, afrontado desde una perspectiva que conflictualiza las tesis del viejo realismo socialista, ha interesado mucho a los críticos que se han ocupado de Después del día de fiesta, quienes mayoritariamente se han inclinado 
por poner el acento en ese giro final y en darle una lectura de signo positivo (Morell, 1997: 671-673; Blanco de García, 1998: 266-267; Saint André, 1998: 80, 84-86; Morell, 1999-2000: 501, 506-509; Tarantuviez, 2001: 91, 112-124, 132-133; Blanco de García, 2008: 99-100). No ha faltado, sin embargo, quien ha subrayado el momento de decepción y el estatus de dios menor en que queda así la poesía (Salerno, 1998: 590). El final sabe, en efecto, a premio de consolación ante las enormes expectativas que se habían generado en torno al verso leopardiano. Más relevante, en cualquier caso, para nuestra tesis sobre la desmitificación es que dicho verso carezca de autoría a lo largo de casi toda la novela. Tampoco los fragmentos de prosa traducidos o parafraseados a modo de opiniones o comentarios de Giacomino se dice de modo inequívoco que formen parte de lo que escribe. Sólo el pasaje de la madre desnaturalizada por exceso de rigor cristiano aparece entrecomillado (Gambaro, 1994: 157-159, traducción de Zibaldone, 353-355), y los párrafos anterior y posterior dejan claro que sale de la pluma de Giacomo, pese a lo cual se le otorga un párrafo aparte, separado -antes y después- por el mismo espacio blanco que en el resto de la novela indica cambios de escenario y de temática, como si se quisiera dar también a este texto esa autonomía anónima de que gozan los versos sobre la noche. El guiño al lector culto pasa, en definitiva, o por camuflar la naturaleza y origen literarios del material utilizado, o por ocultar o diluir la paternidad del mismo. Si nos inclinamos, pues, por ver en Después del día de fiesta un homenaje a la obra leopardiana, parecería más bien colegirse que dicho homenaje se lleva a cabo, en cierto modo, y paradójicamente, contra su autor.

Pero también cabe interpretar que se trata de un homenaje más bien tibio. Un leopardista no calificaría de profundo y extenso el conocimiento de la obra de Leopardi que trasluce la novela, y reprocharía lo poco actualizadas que están las fuentes bibliográficas, detalles más criticables -desde luego- de un estudio filológico que de una recreación artística, pero quizá sí indicativos de una devoción no propiamente desmedida. Si bajamos de nuevo al cuerpo diegético del texto, Giacomino no para de escribir, ríos y ríos de tinta a los que Tristán, sin embargo, no presta la menor atención, repelido por la extraña caligrafía con que están trazados, mientras que sí se desvive por leer las cartas de Paolina que llegan desde Italia. En la escena del recital improvisado que ofrece Giacomo en la plaza de Córdoba, la pareja que lo escucha embelesada le replica con versos de varios autores 
argentinos que son así equiparados en importancia a los pocos de Leopardi que se transcriben. Sobresalen, por la honda impresión que producen en el propio Giacomo, los de Alejandra Pizarnik (Gambaro, 1994: 107-114). Versos, dicho sea de paso, de una mujer, y de una mujer mítica también en su lejanía, en este caso la lejanía que da la muerte.

Por último, invitan también a relativizar el papel de la obra leopardiana en Después del día de fiesta las declaraciones realizadas por Griselda Gambaro fuera de la novela, en varias entrevistas en las que parece dar preeminencia a su fascinación por el Leopardi persona o personaje, más que por el Leopardi poeta: "Leopardi es un personaje entrañable además de un gran poeta" (Tarantuviez, 2001: 81-82); "Fue fácil con Leopardi, un personaje novelesco si los hay” (André, 2004: 67).

Puede resultar extraño que un itinerario vital tan poco byroniano como el del jorobado de Recanati haya levantado tanta curiosidad, pero ha sido así desde siempre. De hecho, cabe entender las tres lecturas aquí analizadas como una vuelta atrás a los primeros tiempos de la recepción leopardiana, es decir, a finales del xix y principios del xx, cuando la crítica se mantenía muy ligada a la biografía y, según los cánones del naturalismo y el psicologismo, veía a Leopardi como un auténtico ‘caso clínico'. A menudo tras tales planteamientos se escondía o se mostraba abiertamente una reacción de rechazo al pensamiento del autor, lo que evidentemente no vale para nuestros tres escritores, menos que menos para Griselda Gambaro, quien hace exactamente lo contrario: por un lado, Leopardi entra en su libro para que se establezca una sintonía entre el mensaje desalentador que transmite la obra del poeta italiano y el que la novelista pretende comunicar (Capano, 2000: 213, 220-221; Tarantuviez, 2001: 81-84), y por otro, y simultáneamente, el Leopardi ‘caso clínico' es colocado en la misma constelación de todos los demás desamparados de la novela, lo que implica que la ficcionalización histórica se lleva a cabo no tanto para reflexionar sobre la identidad americana como para dar al conjunto del cuadro, con la inclusión de un personaje europeo del siglo XIx (al lado, recordemos, de colectivos actuales procedentes del tercer mundo), una proyección más universal y atemporal. En dicha constelación de desamparados se inscribe también Paolina, pero ella, respecto a su hermano, a Tristán, a N’Bom, al Quejoso, ofrece una imagen menos deslucida, más decorosa. Su cárcel de Recanati tiene la ventaja de dejarla fuera de la corte de los milagros que configuran los 
demás, inmersos en una periferia bonaerense pintada con toques sórdidos y tremendistas. Tiene también sus zonas de sombra, pero -como hemos visto- la envuelve un halo de prestigio que casi nunca se resquebraja, un halo que se ilumina con todos los atributos del mito femenino. Participa, por así decirlo, de todos los estadios del ánima de Jung, desde la sabiduría y la espiritualidad hasta el erotismo. Plasma su sensibilidad y poder creativo en una producción literaria -el epistolario- que en manos de Gambaro gana en fuerza e interés, pero desahoga también, en algunas de las cartas, su sexualidad, con un lenguaje lógicamente mucho más explícito que el de la Paolina real, y con una corporeidad no orientada, como en Giacomo, a la deformación carnavalesca, sino -mediante un registro más serio, y dentro de los cánones feministas (Ciplijauskaité, 2004: 337-355; Abud Martínez, 2008: 42-45, 119-128, 228-238) - al descubrimiento de sí misma:

Cómo atreverme entonces, cuando mis gestos están llenos de recato y sumisión -y no obstante sospecha-, cómo atreverme a mostrar lo que guardo, el deseo de amar, de ser amada, los apetitos insaciables que asaltan mi cuerpo, cadáver que no se resigna y resucita (son apetitos e insaciables por lo nunca saciados, se vuelven rabiosos cuando alimentados se tornarían domados, tiernos y tan lícitos, ¿verdad, Giacomuccio, que serían lícitos?) (Gambaro, 1994: 86-87).

El capítulo de Arrieta, muy especialmente, se abre a lecturas de orden psicoanalítico: mientras que Giacomo está resentido por igual con su padre y con su madre, Paolina se levanta en defensa del primero frente a la segunda (1923: 80-82). Es, por otro lado, el único capítulo del libro en el que se insinúa el tema del incesto:

La correspondencia epistolar entre Giácomo y Paulina, abunda en apasionadas expresiones que, tomadas aisladamente, darían motivo a graciosos equívocos. "Te amo como antes, que no era poco, y acaso más que entonces, lo que no es fácil" -léese en una carta del poeta. Y en otra de la hermana: "Decirte cuánto te amo y con cuánta impaciencia y frenesí anhelo verte, es inútil, pues bien que lo imaginarás” (85-86).

Aquí se halla, de hecho, la clave de la mitificación del personaje, porque decir que Paolina goza de los atributos del mito femenino equivale a decir, 
ante todo, que goza de los atributos propios de la mujer en cuanto figura central de la dialéctica amorosa, punto en el que coinciden, en mayor o menor grado, Arrieta, Gambaro y Butti ${ }^{2}$. En Después del día de fiesta no se lee indicación explícita alguna sobre "graciosos equívocos", ni parece que su autora haya querido explorar demasiado ese camino, pero el lector deseoso de adentrarse en él encontrará aquí y allá -entre líneas- algunas posibles brechas. Paolina, ante las mujeres de ese país fabuloso en el que imagina o sueña que está Giacomo, se expresa a veces con evidentes celos (Gambaro, 1994: 122, 138, 140). Los reproches a su hermano por querer verla casada y dar su consentimiento a todos los pretendientes pueden interpretarse también en el mismo sentido (61), y este consentimiento no parece estar tan claro cuando llega la hora de la verdad, como pondría de relieve el canto Nelle nozze della sorella Paolina: “¿Qué te pasó que era tan lúgubre?” (43). Giacomino vive pendiente de la llegada de la correspondencia de su hermana como lo haría un enamorado (84-85), y como una enamorada lamenta ella la pérdida de la compañía de él (28-31). Si -como afirma Giuliano Baioni (1991 [1969]: 197) siguiendo a Leslie A. Fiedler (1973 [1966])- el incesto no sólo proyecta un deseo de rebelión sino también de muerte, las variaciones que se permite Gambaro respecto a las preguntas de la Paolina histórica acerca de las posibles consecuencias del ateísmo de Giacomo (Pascal, 1921: 33-46) aúnan muerte y rebelión en lo que suena con la vehemencia pasional de un amor más allá de la muerte:

Si no te encuentro allí, el Paraíso dejará de serlo. Y me haré la pregunta terrible: ¿̇valió la pena? [...] Y si supiera que serás castigado por tu descreimiento, preferiría condenarme yo también para encontrarte donde quiera que estés, Dios me perdone (Gambaro, 1994: 89).

${ }^{2}$ Añadiríamos a estos tres nombres el de Antonio Aliberti, aunque sólo nos induzcan a hacerlo las pocas líneas que dedicó a Paolina dentro de una cronología leopardiana: "Lo une a la hermana Paolina un fuerte sentimiento. La siente igual a él, sólo que ella no ha podido escapar. Ha quedado bajo la mano férrea de la madre [...] Giacomo ama profundamente a su madre y sufre por su indiferencia. Podría decirse que Paolina es la única mujer que amó a Leopardi”. Aliberti, además, en dicha cronología, facilita como única referencia bibliográfica, con relación a Adelaide Antici y Paolina, el libro de Pascal, lo que confirma la importante mediación de este volumen en el conocimiento de la biografía de los Leopardi por parte de los intelectuales argentinos (Aliberti, 1999: 65-66). 
Pero, dentro de Después del día de fiesta, no sólo determinadas manifestaciones emotivas se mueven en un territorio que podría ser común a un amor fraternal y uno no fraternal, sino que se producen varios acercamientos sintácticos susceptibles de lecturas de segundo nivel, casi de ser entendidos como lapsus o libres asociaciones de los protagonistas. Tras contemplar un beso excesivamente efusivo de la pareja con la que traba amistad en la plaza de Córdoba, los ojos de Giacomo se posan en un jacarandá y justo en ese momento decide que en su próxima carta debe "contarle a Paolina de esos árboles" (110). O nótese cómo en la siguiente frase cabe leer, forzadamente, "que ninguna mujer lo amaba" y "que Paolina lo había olvidado" no como dos quejas distintas, sino como una sola repetida: "musitó: Dios no existe, y en realidad lo que quería decir era que ninguna mujer lo amaba, que Paolina lo había olvidado, que la gloria le era esquiva, y en el olvido y la decepción, nada existía salvo el dolor" (85).

El que une a Paolina y Giacomo es un amor de lohn, y no es raro, en efecto, que cuando se diluye la frontera entre lo fraternal y lo no fraternal se subraye esta circunstancia:

No sé nada, querido Muccio. Te fuiste tan lejos que no sé si estás en Roma o en un mundo que ni siquiera oí nombrar. Tan lejos que a veces tengo la impresión de que te he perdido también en el tiempo. [...] Trato de no pensar en esto para no desesperarme (28-29).

Cuando, al principio de la novela, Tristán encuentra a Giacomino en su apartamento, éste dice estar buscando a su hermana, y la pregunta "¿Por qué la buscás aquí?” queda sin respuesta $(19,22,28)$. La que propondríamos nosotros sería que la busca en Argentina simplemente porque lo importante es que la busque en un lugar lejano, un lugar que ella en sus cartas pueda imaginar como una tierra paradisíaca y feliz (30-31). Aparentemente la distancia aumenta el dolor, pero en realidad provoca el efecto contrario. De ahí la paráfrasis, en boca del propio Giacomo, de los pasajes de Dialogo di Torquato Tasso e del suo Genio familiare en los que Leopardi hablaba del amor y lo hacía en consonancia con sus ideas generales sobre la superioridad de lo soñado respecto a lo real: "no sé si es más dulce ver a la mujer amada o pensar en ella [...] Presente, la mujer amada sólo me parece una mujer, lejana me parecía y me parece una diosa” (64).

De antemano, pocas afinidades cabría esperar entre el elogio de la pure- 
za y la abnegación lanzado por Arrieta en 1923 y el feminismo que subyace, más de setenta años después, en la novela de Gambaro, y sin embargo ambos, así como Butti, se mantienen fieles a unos mismos arquetipos, los de la mujer bondadosa víctima de los demás y los de la mujer ausente, objeto de deseo o abandono. Que los tres escritores cierren filas en torno al mito de la mujer amada más bien limita o matiza la potencialidad subversiva de los dos textos de los años noventa. Mutatis mutandis, los estímulos que ofrece el capítulo de 1923 a un enfoque psicoanalítico invitan a verlo desde una óptica menos conservadora, más cercana a corrientes de pensamiento que en las primeras décadas del siglo estaban a la vanguardia. El innegable abismo temporal, estético e ideológico que los separa no es, por tanto, ni mucho menos absoluto, y de algún modo el leopardismo ayudó a hacerlo menos profundo.

Falta, entre los arquetipos, el de la belleza: Arrieta cita el famoso párrafo en que Paolina describe su físico poco agraciado (1923: 84-85), y Gambaro acusa a Carlo Pascal (1921: 62) de querer encubrirlo y mistificarlo (1994: 138), si bien en otro punto actúa de modo no muy distinto al del biógrafo italiano: "Era flaca y fea, [...] Pero también ella, como Giacomino, albergaba una dulzura secreta, un poco triste, que si uno tenía suficiente paciencia para descubrirla, podía hacer olvidar la fealdad" (186). Tampoco era hermosa -recordemos-Safo, y sobre este detalle escribió precisamente un poema Leopardi. En España y Latinoamérica el Ultimo canto di Saffo, en que el autor habla a través de la poetisa griega, ha recibido -tanto en lo que se refiere a traducciones como a estudios- una atención especial, lo que sería otro indicio de la predilección, dentro del área de recepción en lengua castellana, por un Leopardi al femenino, como si lo leopardiano suscitara más compasión y a la vez más atracción si se encarnara en una mujer. El propio poeta, a propósito de dicho canto, intentó, como Pascal a propósito de Paolina, mitigar la fealdad de su contrafigura: "Per bruttissima che Saffo potesse essere, che certo non fu, l'antichità, l'oscurità de' tempi, l'incertezza ec. introducono quelle illusioni che suppliscono ad ogni difetto" (Leopardi, 2009 [1822]: 226). Una vez más, la ausencia, la lejanía, que borra los defectos y embellece: la mujer amada, vista como un ser perdido o inalcanzable, equipara su fuerza estética a la del infinito.

Un destacado leopardista español, Antonio Colinas, comentando esta nota de Leopardi relativa a Safo, utiliza precisamente el término 'lejanía': 
"Es su lejanía, su presencia inalcanzable, lo que le subyuga" (1988: 131). Lo emplea también el poeta Jorge Guillén en su traducción de los versos iniciales de La sera del dì di festa, para un "di lontan" al que, de este modo, da mayor espesor fonético y conceptual: "Dulce y sin viento y clara está la noche, / Y sobre los tejados y los huertos / Posándose la luna nos revela / Serena en lejanía la montaña" (Muñiz, 2000: 283). Y es con estos cuatro primeros versos, no sólo con el primero, con los que Gambaro cierra su novela ${ }^{3}$. Gracias a ellos Tristán puede ver, en el lejano horizonte, aunque en realidad no existan, las montañas:

[...] y allá, distantes, fuera de los límites del suburbio dormido, más lejos de las chozas de los negros, de los muros, de los tugurios y de la infelicidad, iluminadas por la luna, sobre la línea misma del horizonte se alzaban, serenas, las montañas (Gambaro, 1994: 197).

Pero para certificar la conexión entre el tema del celebérrimo idilio L’infinito y la figura de Paolina quizá resulte más útil volver a Fiedler y su estudio sobre el incesto en la novelística romántica y gótica: "The forbidden bride becomes the Indeterminate, the Impossible itself; and it becomes difficult to know whether the lover is pursuing his sister or the horizon" (1973 [1966]: 56). Fiedler no cita en ningún punto de su ensayo a Leopardi, pero en esta frase -probablemente sin saberlo- sintetiza el significado del incesto entre hermanos con dos términos profundamente leopardianos: "Indeterminate" y "horizon". Y no otra cosa que garantizar la permanencia de la hermana amada en la lejanía mítica de ese horizonte indeterminado es, precisamente, lo que han perseguido los tres autores argentinos que se han ocupado de Paolina Leopardi, en la que han sabido ver y desarrollar a la vez dos facetas contrapuestas: un alter ego de Giacomo y el Otro, es decir, lo deseado.

${ }^{3}$ Ella los cita sólo en lengua original: "Dolce e chiara è la notte e senza vento, / E queta sovra i tetti e in mezzo agli orti / Posa la luna, e di lontan rivela / Serena ogni montagna”. 


\section{Referencias}

Abud Martínez, E. (2008). La re-visión de la Historia en la ficción de mujeres latinoamericanas: Isabel Allende, Gioconda Belli, Carmen Boullosa y Ana Miranda. Tucson: University of Arizona.

Aliberti, A. (1999). Cronología de la vida y de las obras de Giacomo Leopardi. En Leopardi, G., El pensamiento infinito. Cronologías, cantos, opúsculos morales, pensamientos (pp. 53-72). Buenos Aires: Atuel.

André, M. C. (2004). Griselda Gambaro. Entrevista. En André, M. C. (ed.), Antología de escritoras argentinas contemporáneas (pp. 65-69). Buenos Aires: Biblos.

Arrieta, R A. (1923). Paulina Leopardi. En Las hermanas tutelares (pp. 69-89). Buenos Aires: Babel.

Baioni, G. (1991) [1969]. Classicismo e rivoluzione. Goethe e la rivoluzione francese. Nápoles: Guida Editori.

Bellucci, N. (2010). Scritture di donne nell'età della Restaurazione. Dimensioni e Problemi della Ricerca Storica, XXIII, 1, 7-20.

Benucci, E (ed.). (2003). Paolina Leopardi. Atti del Convegno di studi (Recanati, 24-26 maggio 2001). Pisa: ETS.

Biasetti, G. (2009). El poder subversivo de la nueva novela histórica femenina sobre la conquista y la colonización: la centralización de la periferia. Gainesville: University of Florida.

Blanco de García, T. (1998). Calas leopardianas. En Barbolani, C. (ed.), Mentre nel mondo si favelli o scriva. Giacomo Leopardi en el II centenario de su nacimiento (1798-1998) (pp. 251-267). Madrid: Universidad Complutense. (dir.). (2008). Repertorio bibliográfico de las relaciones entre las literaturas argentina e italiana. Córdoba: Ediciones del Copista.

Butti, E. M. (1993). Hermanos. En SolFeo (pp. 67-68). México: Corunda.

Capano, D. A. (2000). La "fiesta" leopardiana en una bioficción de Griselda Gambaro. Alba de América, 35-36, 201-222.

Ciplijauskaité, B. (2004). La construcción del "yo" femenino en la literatura. Cádiz: Universidad de Cádiz.

Colinas, A. (1988). Hacia el infinito naufragio. Una biografía de Giacomo Leopardi. Barcelona: Tusquets.

Crolla, A. (2008). Memorias de Giacomo Leopardi en la literatura argentina. $K A F, 1,39-43$.

Del Greco, A. A. (1952). Giacomo Leopardi in Hispanic Literature. Nueva York: S.F. Vanni.

Dolfi, A. (1991). Paolina Leopardi: esistere nella malinconia. En Dolfi, A. (ed.), Malinconia. Malattia malinconica e letteratura moderna (Atti di seminario. Trento, maggio 1990) (pp. 239-256). Roma: Bulzoni. 
Fiedler, L. A. (1973) [1966]. Love and death in the American novel. Nueva York: Stein and Day.

Galli de Ortega, G. (1999). La recepción argentina de Leopardi. En Steimberg de Kaplán, O. R.; Flores de Molinillo, E. y Borkosky de Domínguez, M. (eds.), Literatura: Espacio de contactos culturales. Cuartas Jornadas Nacionales de Literatura Comparada (Tucumán, 12 al 15 de agosto de 1998) (vol. 3, pp. 1221-1230). Córdoba: Comunicarte Editorial / Asociación Argentina de Literatura Comparada.

Gambaro, G. (1994). Después del día de fiesta. Buenos Aires: Espasa Calpe Argentina / Seix Barral.

Gioanola, E. (1995). Leopardi, la malinconia. Milán: Jaca Book.

Grillo, R. M. (2010). Escribir la historia: descubrimiento y conquista en la novela histórica de los siglos xix y xx. Alicante: Universidad de Alicante.

Leopardi, G. (2009 [1822]). Premessa all'Ultimo canto di Saffo. En Canti. (Ed. Franco Gavazzeni y Maria Maddalena Lombardi). Milán: Rizzoli.

Morell, H. R. (1997). Después del día de fiesta: reescritura y posmodernidad en Griselda Gambaro. Revista Iberoamericana, 181, 665-674.

(1999-2000). Leopardi en Después del día de fiesta de Griselda Gambaro: el poeta y la realidad humana argentina finisecular. Río de la Plata, 2O-21, 501-510.

Muñiz, M. de las N. (2000). Leopardi in Spagna: pensiero/poesia e ricezione. En Muñiz, M. de las N. (ed.), Giacomo Leopardi. Poesia, pensiero, ricezione. Nel bicentenario della nascita del poeta (1798-1998). Atti del Convegno Internazionale di Barcellona (5-7 marzo 1998) (pp. 273-294). Leonforte: Insula.

Pascal, C. (1921). La sorella di Giacomo Leopardi. Milán: Fratelli Treves.

Perkowska, M. (2008). Historias híbridas. La nueva novela histórica latinoamericana (1985-200o) ante las teorías posmodernas de la historia. Madrid: Iberoamericana.

Saint André, E. (1998). Propuestas estéticas para el fin de siglo en Después del día de fiesta de Griselda Gambaro. En Saint André, E. y Rolón, A. (eds.), Cuando escriben las mujeres (pp. 77-86). San Juan: Universidad Nacional de San Juan.

Salerno, M. (1998). Leopardi en una novela de Griselda Gambaro. En AA.VV., Actas de las Terceras Jornadas Nacionales de Literatura Comparada (Vaquerías (Córdoba), 22 al 24 agosto de 1996) (vol. 1, pp. 585-591). Córdoba: Comunicarte Editorial / Asociación Argentina de Literatura Comparada.

Tarantuviez, S. (2001). La narrativa de Griselda Gambaro. Una poética del desamparo. Mendoza: Universidad Nacional de Cuyo. 